\title{
Anesthetic management for emergency caesarean section and craniotomy together: an overview of the challenge
}

\author{
Nidhi Pathak, Misha Katyal*
}

Department of Anesthesiology, Safdarjung Hospital, New Delhi, India

Received: 09 February 2020

Accepted: 04 March 2020

*Correspondence:

Dr. Misha Katyal,

E-mail: katyal.misha@gmail.com

Copyright: (C) the author(s), publisher and licensee Medip Academy. This is an open-access article distributed under the terms of the Creative Commons Attribution Non-Commercial License, which permits unrestricted non-commercial use, distribution, and reproduction in any medium, provided the original work is properly cited.

\begin{abstract}
Traumatic brain injury in a pregnant woman is a challenge for anaesthesiologist, surgeon as well as paediatrician as it involves care and management of two lives together. We hereby discuss anaesthetic management of a 23 year old pregnant woman with extra axial bleed and brain contusion and skull fracture. Since the fetus was viable without signs of fetal distress, decision of doing caesarean section followed by craniotomy was taken and our patient was discharged a week later and the baby was handed over to attendant the next day.
\end{abstract}

Keywords: Anesthesia, Cesarean section, Craniotomy, Extra axial bleed

\section{INTRODUCTION}

Trauma affects $7-8 \%$ of all pregnancies. ${ }^{1,2}$ Caesarean section with craniotomy requires a multidisciplinary and multisystem approach as it involves 2 lives, i.e. mother and fetus. It involves thorough discussion between gynaecologist, neurosurgeon, paediatrician, anaesthesiologist and the patient's attendants. All the risks to the mother and the fetus should be discussed and explained pre operatively to the attendants. The possible complications like blood loss, distress to fetus, long term post-operative ventilation and ICU stay should be anticipated and managed accordingly. We should keep in mind that the risk of high intracranial pressure, hypotension, anemia or expanding mass lesions in the cranial cavity can threaten both maternal and fetal life. ${ }^{3}$

\section{CASE REPORT}

This case report a 23 years old female (G3A2) with history of 9 months amenorrhea with $36+2$ weeks gestation age with history of fall from auto rickshaw followed by unconsciousness, ENT bleed, vomiting and scalp laceration. She presented to emergency department (ED) one hour after the accident. When she presented to emergency department her GCS was E2V1M4, blood pressure of $130 / 73 \mathrm{mmHg}$, heart rate of $78 / \mathrm{min}$, respiratory rate of $24 / \mathrm{min}, \mathrm{SpO}_{2}$ of $98 \%$, blood glucose $104 \mathrm{mg} / \mathrm{dl}$. Her pupils were dilated on left side and normal size on the right side.

A scalp hematoma was noticed over left fronto-parietal region.

$18 \mathrm{G}$ peripheral IV cannula was taken. Patient was intubated in ED in view of poor GCS. All investigations were sent including complete blood count, kidney function test, liver function test, serum electrolytes, blood sugar, and coagulation tests. Computed tomography (head) in view of poor maternal neurological condition was done after explaining the risks to the attendants.

Computed tomography revealed extra axial bleed and sub arachnoid hemorrhage in left fronto parietal region and multiple contusions in left fronto parietal region and splenium of corpus callosum. Midline shift towards right was seen. Fracture of right parietal bone extending to 
mastoid and squamous part of temporal bone was also seen (as seen in Figure 1 and 2).

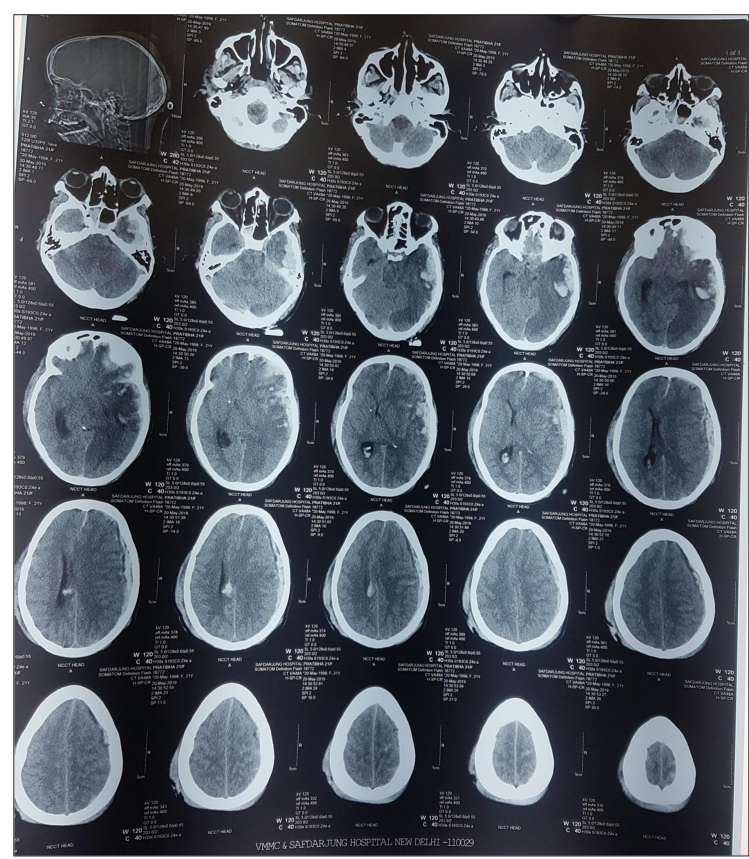

Figure 1: CT head of the patient.

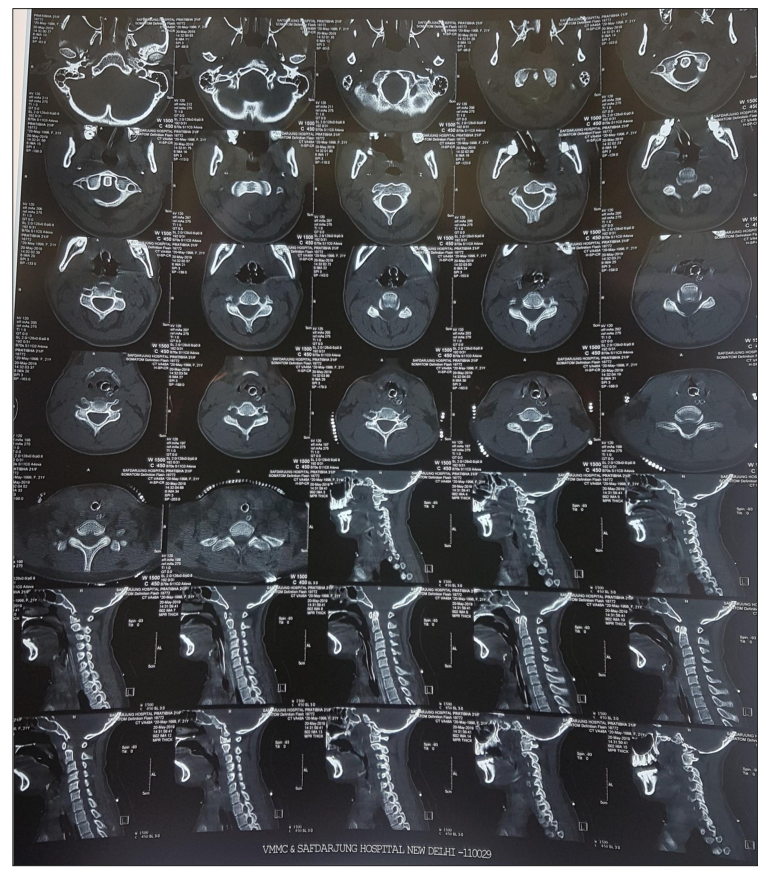

Figure 2: CT neck of the patient.

Cervical spine was grossly normal.

Focused assessment with sonography for trauma (FAST) was done and was negative for any other injury.
No other injuries were detected.

Obstetrician did clinical examination. Per abdomen examination revealed uterus 36 weeks size, cephalic presentation, head was floating, fetal heart sound +, uterus relaxed and was non tense. Per vaginal examination revealed os closed, cervix effaced, pelvis adequate.

\section{Results of investigation were}

Hemoglobin-11.2, platelet count- $1,51,000 / \mu \mathrm{L}$, total leucocyte count- $10.53 X 10^{9} / \mathrm{L}$, S. urea- $10 \mathrm{mg} / \mathrm{dl}$, S. creatinine $-0.70 \mathrm{mg} / \mathrm{dl}$, serum electrolytes- sodium- 134 $\mathrm{meq} / \mathrm{dl}$, potassium-3.3 meq/dl, LFT- WNL, coagulation tests- PT-12.9 secs, INR- 0.92 .

All the risks and benefits of surgery were explained to the attendants and consents were taken.

After thorough discussion with neurosurgeon and the family members of the patient, decision of simultaneous emergency cesarean section and craniotomy was taken.

Adequate blood products were arranged and surgery was started with 2 units of packed red blood cells in hand.

Patient was shifted to operation theatre and monitors were attached (NIBP, ECG, $\mathrm{SpO}_{2}$ ) and baseline vitals were noted.

Preoperative vitals- HR- $88 / \mathrm{min}$ (regular), blood pressure- $128 / 80 \mathrm{mmHg}, \quad \mathrm{SpO}_{2}-100 \%$, ECG-WNL, respiratory system- $\mathrm{B} / \mathrm{L}$ clear, no added sounds, cardiovascular system- S1S2 normal, no murmurs.

Invasive blood pressure monitoring was done by inserting an arterial line in the left radial artery.

Central venous cannulation was done in the right internal jugular vein with 7 Fr triple lumen central line.

General anesthesia was induced. As the patient was already intubated, injection fentanyl $50 \mu \mathrm{g} \mathrm{IV}$, thiopentone $200 \mathrm{mg}$ IV and vecuronium $5 \mathrm{mg}$ IV was given and patient was put on ventilator (volume control mode- tidal volume- $400 \mathrm{ml}$, frequency- $12 / \mathrm{min}$, PEEP- 5 $\mathrm{cm}$ of water). Isoflurane $0.6 \%-1 \%$ in $60 \%$ oxygen in air mixture was used to maintain anesthesia.

Ryles tube was inserted for gastric emptying. Intermittent injection vecuronium $1 \mathrm{mg}$ IV was given for muscle relaxation.

A wedge was placed below the right hip.

EtCO2 was maintained at $\sim 32 \mathrm{mmHg}$ throughout the surgery. 
Cesarean section was conducted first. A 2500 gm male infant was delivered by lower section cesarean section after 7 mins of induction of anesthesia with Apgar scores of 5 and 7 at 1 and 5 mins respectively. The baby was kept in neonatal ICU and was further managed by pediatricians. On follow up it was found that the baby was handed over to attendants on the next day.

After delivery oxytocin $5 \mathrm{U}$ slowly over 5 mins followed by infusion of $15 \mathrm{U}$ in $500 \mathrm{ml}$ of Normal Saline over 4 hours was given.

Post cesarean vitals- HR- 98/min (regular), blood pressure- $110 / 70 \mathrm{~mm}$ of $\mathrm{Hg}, \mathrm{SpO}_{2}-100 \%$, ECG-WNL, respiratory system- $\mathrm{B} / \mathrm{L}$ clear, no added sounds, cardiovascular system- S1S2 normal, no murmurs.

Injection fentanyl $100 \mu \mathrm{g}$ was given again after delivery of the baby and then craniotomy with evacuation of the extra axial bleed and contusion was done.

Blood loss in cesarean section was around $800 \mathrm{ml}$ and in craniotomy blood loss was around 700-800 ml. Maximum allowable blood loss was one liter (keeping target hemoglobin of $9 \mathrm{gm} \%$ ). Two units of packed red blood cells were administered.

Intra-operatively patient was also given $1 \mathrm{~g}$ paracetamol IV infusion. Urine output was maintained at $>1$ $\mathrm{ml} / \mathrm{kg} /$ hour.

Post craniotomy vitals- HR- 106/min (regular), blood pressure- $102 / 68 \mathrm{~mm}$ of $\mathrm{Hg}, \mathrm{SpO}_{2}-100 \%$, ECG-WNL, respiratory system- $\mathrm{B} / \mathrm{L}$ clear, no added sounds, cardiovascular system- S1S2 normal, no murmurs.

The patient was transferred to the neurological ICU and was put on volume control mode. On follow up it was found that patient was kept in Neuro ICU for 4 days and slowly weaned and discharged a week after the surgery.

\section{DISCUSSION}

Trauma affects $7-8 \%$ of all pregnancies. ${ }^{1,2}$ The risk of systemic and cerebral complications of high intracranial pressure, hypotension, anemia or expanding mass lesions in the cranial cavity can threaten both maternal and fetal life. ${ }^{3}$

Cervical spine injury should be ruled out. Radiographic studies indicated for maternal evaluation, including abdominal computed tomography, should not be deferred or delayed due to concerns regarding fetal exposure to radiation. $^{4}$

Now we had option of either continuing pregnancy and performing craniotomy and doing delivery of the baby if any fetal distress develops or doing cesarean section and craniotomy simultaneously. Since vaginal delivery after a neurosurgery can be dangerous as it may lead to increase in intra cranial pressure due to straining or uterine contractions.

Another decision was to be taken about the order of surgery. That is craniotomy first or cesarean section should be done first. Though doing craniotomy first might improve neurological outcome by early surgical evacuation but due to prolonged exposure to anesthetic drugs, maternal hypotension and specific drugs (e.g., mannitol) fetal risk increases, thus the decision of doing cesarean first was taken for better fetal and maternal outcomes.

Usual anesthetic considerations for neurosurgeries need to be modified in a pregnant patient. For example controlled hypotension, hypothermia, hyperventilation and osmotic diuresis need to be conducted with particular care in pregnancy. Uteroplacental perfusion may significantly decrease with reduction of mean arterial pressure below $70 \mathrm{mmHg}$. If hypothermia is used, it may lead to reduction in fetal heart rate. Extreme hyperventilation may lead to uterine artery vasoconstriction leading to further decrease in uterine perfusion. Negative fluid shifts may occur in fetus with osmotic dieresis. Mannitol especially can lead to decreased renal blood flow, increase in osmolarity and increased plasma sodium concentration in fetus. ${ }^{5}$

Authors should always keep in mind the changes in maternal airway during pregnancy. The increase in peripheral blood flow and vascularity results in airway edema and friability. We may find these changes from second trimester. Mallampatti classification relates more with difficult intubation in pregnancy. Difficult airway cart should be handy while doing intubation in pregnant women. ${ }^{5}$

Since maternal analgesia with fentanyl $[1$ microg x kg (1)] is not associated with adverse neonatal effects we used $50 \mu \mathrm{gm}$ of fentanyl before cesarean and supplemented analgesia with injection paracetamol infusion. Rest of the fentanyl was given after delivery of the fetus. ${ }^{6}$

For induction, we had options of thiopentone, propfol, etomidate and ketamine. All have been used for cesarean section, but since it was combined with neurosurgery we opted for thiopentone as it is the preferred induction agent of choice for neurosurgery cases. Thiopentone causes dose dependent depression of cerebral metabolic rate of oxygen and parallel reduction in Cerebral blood Flow and Intra cranial pressure without compromising cerebral perfusion pressure. It also has anticonvulsant properties.

Skeletal muscle relaxants have no effect on uterine muscle tone and in standard doses all classes of muscle relaxant are poorly transferred to fetus. ${ }^{5}$ These non depolarizing muscle relaxants are safe for neuro-surgery also. This case used injection vecuronium. 
For maintenance - low concentrations of volatile anesthetics may be used as high concentrations of these for long time may lead to neonatal flaccidity, cardio respiratory depression and reduced tone all of which respond to assisted ventilation to facilitate exhalation of the inhalational agents. ${ }^{5}$ Since isoflurane is preferred for the neurosurgical patient because it causes no depression of myocardial function, no increase in intracranial pressure and cerebral perfusion pressure is maintained; in this case isoflurane was used in the patient. ${ }^{8}$

Talking about analgesia non-steroidal anti inflammatory drugs should be used with caution during pregnancy. They are associated with an increased risk for fetal malformation and miscarriage when used during early pregnancy and premature closure of the ductus arteriosus and oligohydramnios when used after 30 weeks gestation. ${ }^{9}$ Acetaminophen is accepted as safe during pregnancy. $^{5}$

\section{CONCLUSION}

Combining the anaesthetic considerations for both caesarean section and neuro surgery with avoidance of anaesthesia techniques which decrease uterine blood flow and oxygen delivery to fetus or maternal brain leads to favourable outcome of the surgery. The anaesthetic plan which optimizes both the maternal and fetal conditions should be followed.

Funding: No funding sources Conflict of interest: None declared

Ethical approval: Not required

\section{REFERENCES}

1. Mendez-Figueroa H, Dahlke JD, Vrees RA, Rouse DJ. Trauma in pregnancy: an updated systematic review. Am J Obstet Gynecol. 2013;209:1-10.
2. Barraco RD, Chiu WC, Clancy TV, Como JJ, Ebert JB, Hess LW, et al. Practice management guidelines for the diagnosis and management of injury in the pregnant patient: The EAST Practice Management Guidelines Work Group. J Trauma. 2010;69:211-4.

3. Vulkov I, Bozhinov P. Head injury during pregnancy. Akush Ginekol (Sofiia). 2016;55(2):22-6.

4. Kho GS, Abdullah JM. Management of severe traumatic brain injury in pregnancy: a body with two lives. Malays J Med Sci. 2018;25(5):151-7.

5. Flood P, Rollins MD. Anesthesia for Obstetrics. In: Ronald D Miller, Neal H. Cohen, Lars I. Eriksson, Lee A Fleisher, Jeanine, William L. Young. Miller's Anesthesia. $8^{\text {th }}$ Edition, Philadelphia: Elsevier; 2005:2328-2358.

6. Frölich MA, Burchfield DJ, Euliano TY, Caton D. A single dose of fentanyl and midazolam prior to Cesarean section have no adverse neonatal effects. Can J Anaesth. 2006;53(1):79-85.

7. Albrecht RF, Miletich DJ, Rosenberg R. Cerebral blood flow and metabolic changes from induction to onset of anesthesia with halothane and pentobarbital. Anesthesiol. 1977;47:252-6.

8. Frost EA. Inhalation anaesthetic agents in neurosurgery. Br J Anaesth. 1984;56 Suppl 1:47S$56 \mathrm{~S}$.

9. Antonucci R, Zaffanello M, Puxeddu E, Porcella A, Cuzzolin L, Dolores Pilloni M, et al. Use of nonsteroidal anti-inflammatory drugs in pregnancy: impact on the fetus and newborn. Current Drug Metabol. 2012;13(4):474-90.

Cite this article as: Pathak N, Katyal M. Anesthetic management for emergency caesarean section and craniotomy together: an overview of the challenge. Int J Reprod Contracept Obstet Gynecol 2020;9:1717-20. 